\title{
Remote Nucleophilic Allylation by Allylrhodium Chain Walking
}

\begin{abstract}
Alistair Groves, Jose I. Martínez ${ }^{+}$, Joshua J. Smith ${ }^{+}$,
Abstract: Metal migration through a carbon chain is a versatile method for achieving remote functionalization. However, almost all known examples involve the overall net migration of alkylmetal species. Here, we report that allylrhodium species obtained from hydrorhodation of 1,3-dienes undergo chain walking toward esters, amides, or (hetero)arenes over distances of up to eight methylene units. The final, more highly conjugated allylrhodium species undergo nucleophilic allylation with aldehydes and an imine to give $Z$-homoallylic alcohols and amines, respectively.
\end{abstract}

$\boldsymbol{R}$ emote functionalization reactions are those in which an initial interaction of a functional group with a reagent or catalyst leads to eventual reaction at a distal site. ${ }^{[1]}$ Although achieving high efficiency and selectivity in such processes is often challenging, developments in this area can facilitate the activation of otherwise unreactive $\mathrm{C}-\mathrm{H}$ and $\mathrm{C}-\mathrm{C}$ bonds, thus providing powerful new tools for synthesis. Of the available methods for remote functionalization, metal migration through a carbon chain, or "chain walking", is particularly versatile as it dispenses with the need for complex directing groups (Scheme 1A). ${ }^{[19-i, 2,3]}$ However, most known metal chain walking reactions effectively result in the overall net migration of alkylmetal species (Scheme 1A). Chain walking of organometallics beyond simple alkylmetals, such as allylmetal species (Scheme 1B), could dramatically expand the scope of remote functionalizations, but to our knowledge, there are such few examples. ${ }^{[4]}$

During our studies of enantioselective nucleophilic allylations of imines, ${ }^{[4 b, 5]}$ we discovered the first examples of allylrhodium chain walking (Scheme $1 \mathrm{C}) .{ }^{[4 b]}$ These reactions employ $\delta$ trifluoroboryl $\alpha, \beta$-unsaturated esters as precursors to allylrhodium species $\mathbf{A}$. Chain walking of $\mathbf{A}$ towards the ester is proposed to occur via a 1,3-diene-ligated rhodium hydride $\mathbf{B}$ to give the more highly conjugated, and presumably thermodynamically more stable allylrhodium species $\mathbf{C}$, which then reacts with the imine in a highly diastereo- and enantioselective nucleophilic allylation. ${ }^{[4 b]}$

To increase the synthetic utility of allylrhodium chain walking, we wondered whether migration could be accomplished through more than just one methylene carbon. This goal was expected to be challenging because rhodium must participate in a greater number of steps before the final allylrhodium species is formed,

[*] A. G. Groves, Dr. J. I. Martinez, Dr. J. J. Smith, Prof. H. W. Lam The GlaxoSmithKline Carbon Neutral Laboratories for Sustainable Chemistry, University of Nottingham, Jubilee Campus, Triumph

Road, Nottingham, NG7 2TU (UK)

E-mail: hon.lam@nottingham.ac.uk

Homepage: http://www.nottingham.ac.uk/ pczhl/

Dr. J. I. Martinez, Dr. J. J. Smith, Prof. H. W. Lam

School of Chemistry, University of Nottingham, University Park, Nottingham, NG7 2RD (UK)

[+] These authors contributed equally.

Supporting information and the ORCID identification number(s) for the author(s) of this article can be found under: http://dx.doi.org/

\author{
, and Hon Wai Lam*
}

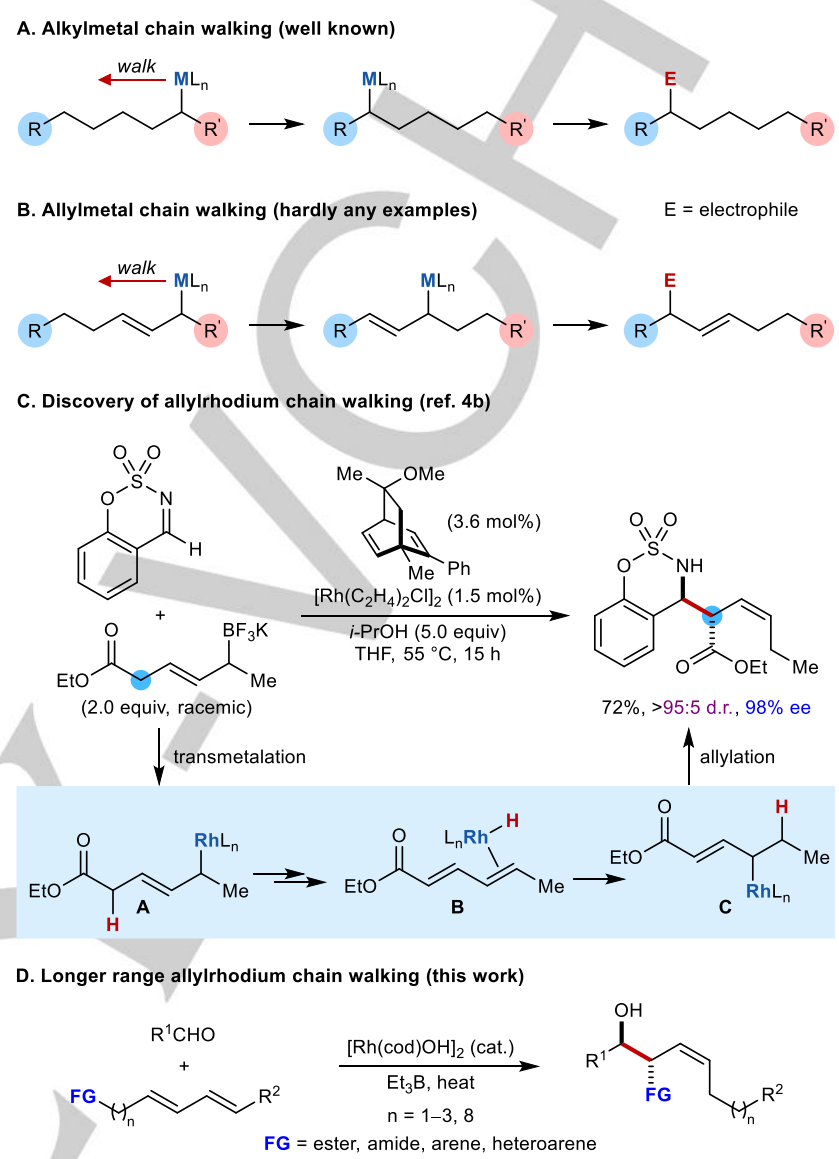

Scheme 1. Metal chain walking.

and in principle, any of the intermediate allylrhodium species can react with the electrophile to give complex mixtures of products. Herein, we describe remote nucleophilic allylations of aldehydes and an imine, in which allylrhodium chain walking occurs through up to eight methylene units (Scheme 1D).

For this study, the use of allylrhodium precursors that are simpler to prepare than allyltrifluoroborates was desirable. We therefore considered generating allylrhodium species by the hydrorhodation of 1,3-dienes, as described by Kimura and coworkers in related reductive nucleophilic allylations. [ 6 [ $]$ Accordingly, substrate 1a was reacted with benzaldehyde (1.2 equiv) in the presence of $[\mathrm{Rh}(\mathrm{cod}) \mathrm{OH}]_{2}(5 \mathrm{~mol} \%)$ and $\mathrm{Et}_{3} \mathrm{~B}(2.0$ equiv) in THF at $50{ }^{\circ} \mathrm{C}$ for $16 \mathrm{~h} .{ }^{[6]}$ Pleasingly, this reaction gave homoallylic alcohol $\mathbf{2 a}$, which was isolated as a single diastereomer in $60 \%$ yield [Eq. (1) and Table 1, entry 1]. ${ }^{[7]}$ The use of $\mathrm{Et}_{3} \mathrm{SiH}$ in place of $\mathrm{Et}_{3} \mathrm{~B}$ gave no reaction.

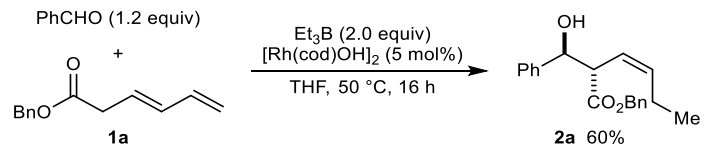

A possible catalytic cycle is shown in Scheme 2. First, the reaction of $[\mathrm{Rh}(\mathrm{cod}) \mathrm{OH}]_{2}$ with $\mathrm{Et}_{3} \mathrm{~B}$ generates the ethylrhodium species 3 , which undergoes $\beta$-hydride elimination to give 


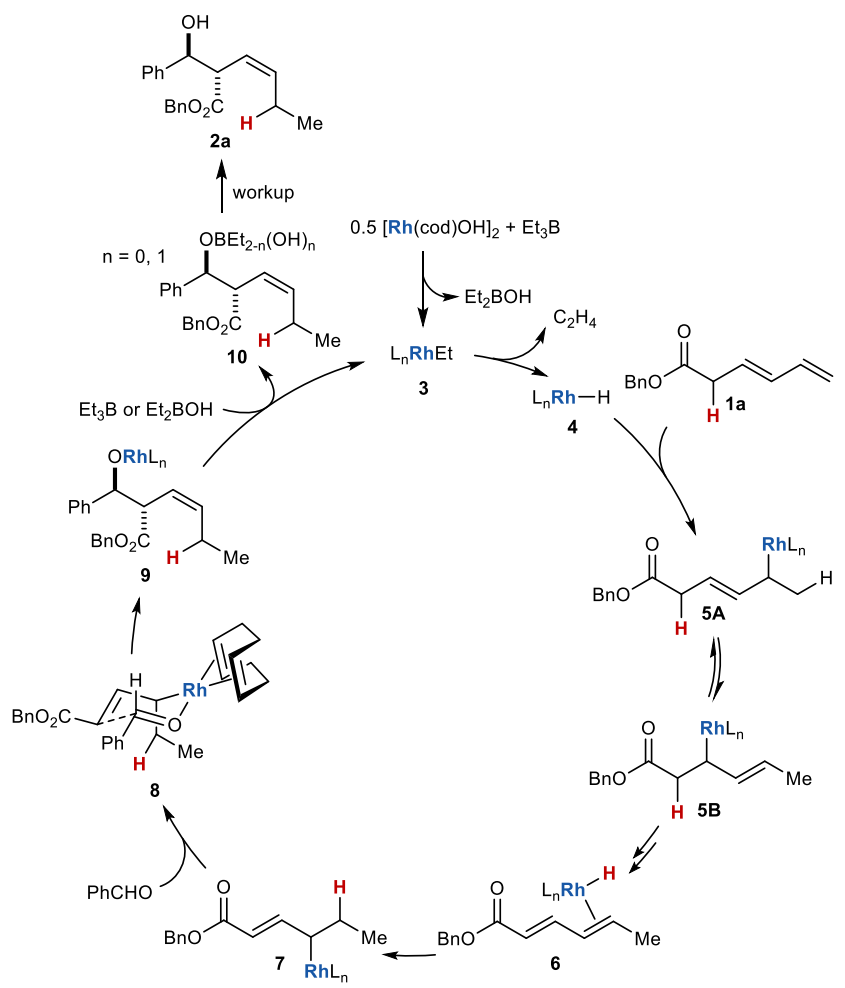

Scheme 2. Proposed catalytic cycle.

rhodium hydride 4. Hydrorhodation of 1,3-diene 1a with 4 then provides allylrhodium species $\mathbf{5 A}$, which undergoes $\sigma-\pi-\sigma$ isomerization to give $5 \mathbf{B} \cdot{ }^{[8]} \beta$-Hydride elimination of $5 \mathbf{B}$ gives a rhodium hydride coordinated to benzyl sorbate (as in 6). Hydrorhodation of the alkene distal to the ester gives allylrhodium species 7 , resulting in an overall 1,4-hydrogen shift from the carbon adjacent to the carbonyl group, to the methylene carbon adjacent to the methyl group. Allylrhodium species 7 then reacts with benzaldehyde in a nucleophilic allylation through conformation $\mathbf{8}$, in which the ethyl group occupies a pseudoaxial position to minimize unfavorable nonbonding interactions with the cyclooctadiene ligand. Reaction of the resulting rhodium alkoxide $\mathbf{9}$ with $\mathrm{Et}_{3} \mathrm{~B}$ or $\mathrm{Et}_{2} \mathrm{BOH}$ gives 10 (which upon workup gives the product $\mathbf{2 a}$ ) and regenerates the ethylrhodium species 3 .

Having established proof of principle, the scope with respect to the diene was investigated (Table 1). One of two sets of conditions were employed. Method A used 2.0 equivalents of $\mathrm{Et}_{3} \mathrm{~B}$ in THF at $50^{\circ} \mathrm{C}$, whereas method $\mathrm{B}$ used 3.0 equivalents of $\mathrm{Et}_{3} \mathrm{~B}$ in dioxane at $80^{\circ} \mathrm{C}$. Method $\mathrm{B}$ was used for reactions that did not proceed in high conversion with method A. Pleasingly, a range of dienes reacted successfully with benzaldehyde to give products of chain walking-nucleophilic allylation 2 in up to $65 \%$ yield. These reactions also gave complex mixtures of other products in ca. $20 \%$ yield, which were tentatively identified as nucleophilic allylation products resulting from various intermediate allylrhodium species. ${ }^{[9]}$ The complexity of the reactions prevented determination of the diastereoselectivities by ${ }^{1} \mathrm{H}$ NMR analysis, but with a few exceptions (entries 7-9), the products 2 were isolated as single diastereomers. In addition to chain walking through one carbon (entries 1 and 2), walking through two carbons (entries 3-8) and three carbons is possible (entries 10 and 11). As well as terminal dienes $\left(R^{2}=H\right.$, entries 1 , 3 , and 10$)$, the process is compatible with internal dienes with various alkyl groups at $R^{2}$ (entries $2,4,6-8$, and 11). However,
Table 1. Scope of the 1,3-diene. ${ }^{[a]}$
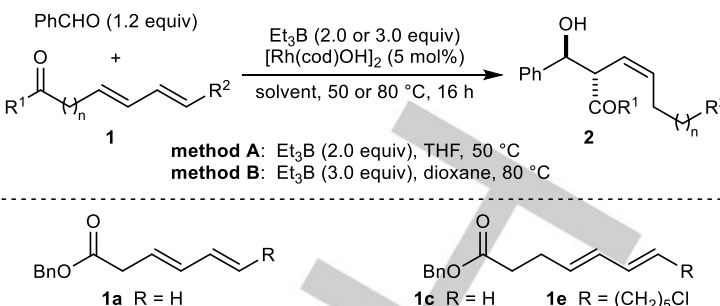
1a $\mathrm{R}=\mathrm{H} \quad$ 1c R $=\mathrm{H} \quad$ 1e $\mathrm{R}=\left(\mathrm{CH}_{2}\right)_{5} \mathrm{Cl}$ 1b $\mathrm{R}=\mathrm{Me} \quad$ 1d $\mathrm{R}=\mathrm{Me} \quad$ if $\mathrm{R}=\mathrm{CH}_{2} \mathrm{OTBDPS}$

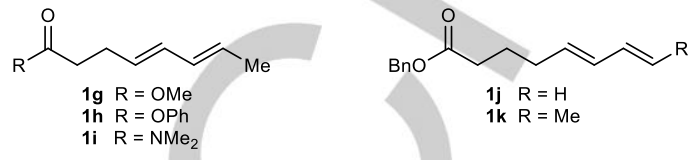

P

\begin{tabular}{llll}
\hline entry diene method product & yield $(\%)^{[\mathrm{b}]}$ \\
\hline walking through one carbon: & 2a 60 \\
1 & $\mathbf{1 a}$ & 2b &
\end{tabular}

walking through two carbons:

34 1c

walking through three carbons:

$10 \quad \mathbf{1} \quad$ B

[a] Reactions were conducted with $0.30 \mathrm{mmol}$ of 1. [b] Yield of isolated product. Unless stated otherwise, the products were isolated as single diastereomers. [c] Conducted with $0.24 \mathrm{mmol}$ of $\mathbf{1 i}$. [d] Isolated as a mixture of inseparable diastereomers in the ratio indicated in parentheses. [e] The reaction time was $40 \mathrm{~h}$. 
diene 1e, which contains a 1-chlorobutyl group, only returned unchanged starting materials (entry 5). ${ }^{[10]}$ Methyl and phenyl esters are also tolerated (entries 7 and 8). An amide also promotes chain walking, but with lower efficiency (entry 9).

Chain walking over greater distances is possible, as shown by the reaction of diene $\mathbf{1 l}$, which contains eight methylene units between the diene and the ester [Eq. (2)].

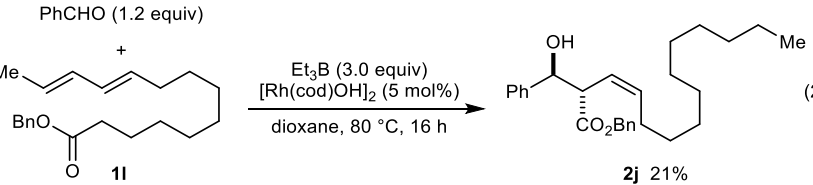

Next, variation of the aldehyde was investigated with diene 1d (Scheme 3). Aromatic aldehydes containing various para-, meta-, or ortho-substituents are tolerated to give 11a, 11b, 11d, and $11 \mathrm{e}$ in $50-62 \%$ yield. 4-Bromobenzaldehyde returned only unchanged starting materials, ${ }^{[10]}$ whereas 2 -furaldehyde gave $11 f$ in $40 \%$ yield. Linear and branched aliphatic aldehydes are also tolerated (11f-11j). Tetrahydro-2H-pyran-2-ol reacted successfully to give $11 \mathrm{k}$ in $58 \%$ yield.

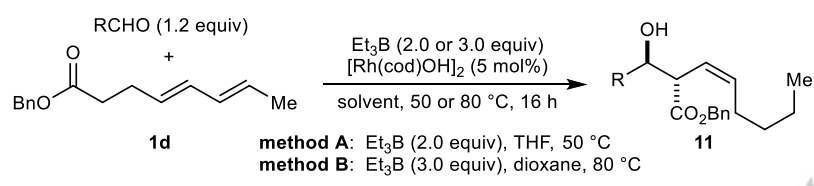

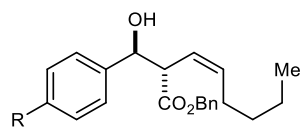

11a $\mathrm{R}=\mathrm{Me}, 58 \%{ }^{[\mathrm{a}]}(\operatorname{method} \mathrm{A})$ 11c $R=B r$, no reaction (method $B$ )<smiles>CC/C=C\C(C(=O)OC(=O)CCCCC)C(O)c1ccccc1OC</smiles>

11e $52 \%(\operatorname{method} A)$<smiles>[M]CCCCC(=O)OC(=O)C([R])O</smiles>

$11 \mathrm{~g} \mathrm{R}=n-\mathrm{Pr}, 38 \%(9: 1 \text { d.r. })^{[\mathrm{b}]}(\operatorname{method} \mathrm{A})$ $11 \mathrm{~h} \mathrm{R}=i-\mathrm{Pr}, 54 \%(16: 1 \text { d.r. })^{[\mathrm{b}]}$ (method B) 11i $\mathrm{R}=$ cyclohexyl, $61 \%$ (method $\mathrm{B}$ ) 11j $\mathrm{R}=t$-Bu, $28 \%(4: 1 \text { d.r. })^{[b]}$ (method $\left.\mathrm{B}\right)$

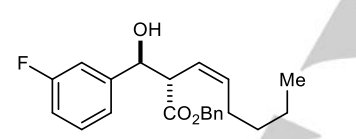

11d $50 \%$ (method B)<smiles>[M]CCCCC(=O)OC(C)C(O)c1ccco1</smiles>

11f $40 \%[$ [a] $(\operatorname{method} B)$

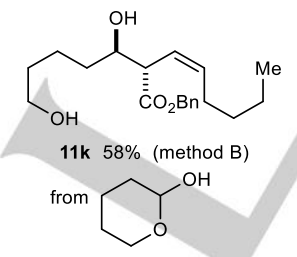

Scheme 3. Scope of the aldehyde. Reactions were conducted with $0.30 \mathrm{mmo}$ of 1d. Unless stated otherwise, yields are of isolated, single diastereomers. [a] The diastereoselectivity was $>19: 1$ d.r. as determined by ${ }^{1} \mathrm{H}$ NMR analysis of the crude reaction. [b] Isolated as a mixture of inseparable diastereomers in the ratio indicated in parentheses.

Interestingly, diene $\mathbf{1} \mathbf{m}$, which contains an ester and a phenyl group at the termini, reacted with benzaldehyde to give a mixture of products differing in the direction of chain walking [Eq. (3)]. The product of chain walking towards the ester $(\mathbf{2 k})$ was isolated in $15 \%$ yield, while product $\mathbf{1 2}$, resulting from chain walking towards the phenyl group, was obtained in $31 \%$ yield.

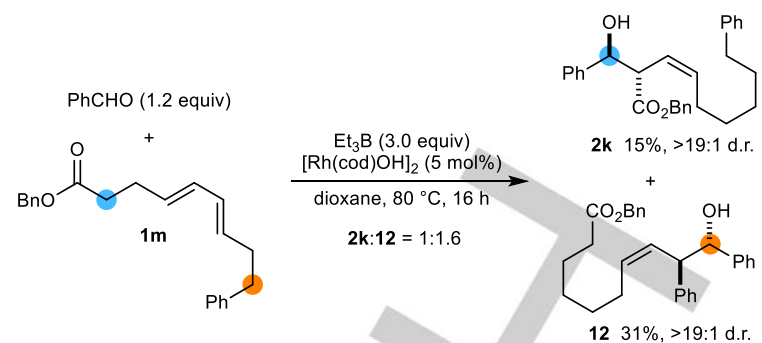

The discovery that arenes also promote allylrhodium chain walking significantly increases the possibilities of this chemistry, and this aspect was explored further in the reaction of dienes 13a-13g with benzaldehyde (Scheme 4). As expected, the phenyl-terminated diene 13 a reacted successfully to give $14 a$ in $50 \%$ yield. ${ }^{[7]}$ Other arenes that bring about chain walking include 2-naphthyl (14b), 2-fluorophenyl (14c), and 3-methoxyphenyl groups (14d). Pleasingly, heteroarenes such as 2-pyridyl (14e), 2-furyl (14f), and 2-thienyl (14g) groups are also effective.
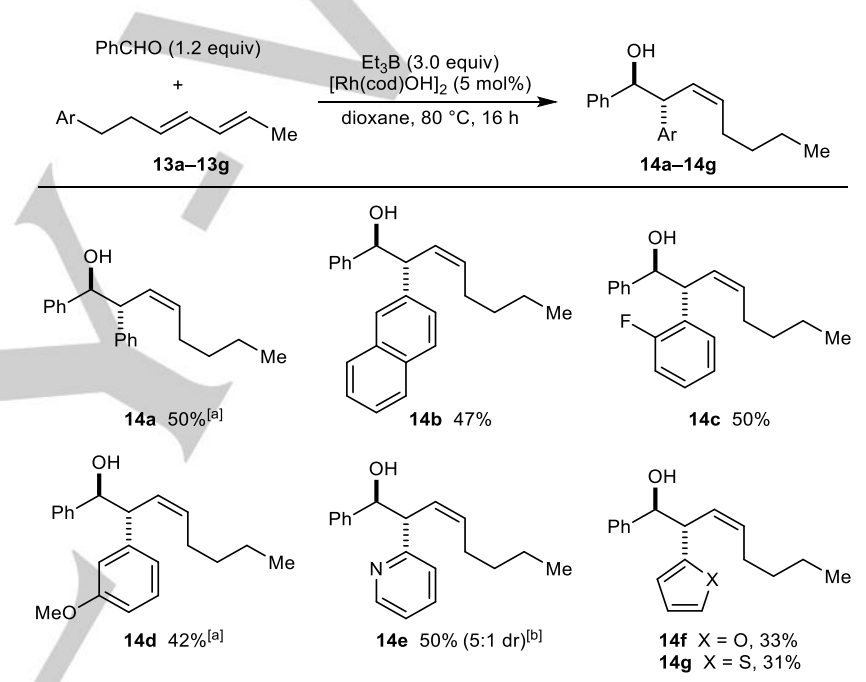

Scheme 4. Scope of the 1,3-dienes with a (hetero)arene terminus. Reactions were conducted with $0.30 \mathrm{mmol}$ of 13. Unless stated otherwise, yields are of isolated, single diastereomers. [a] The diastereoselectivity was >19:1 d.r. as determined by ${ }^{1} \mathrm{H}$ NMR analysis of the crude reaction mixture. [b] Isolated as a mixture of inseparable diastereomers in the ratio indicated in parentheses.

An advantageous feature of these reactions is that the stereochemistry of the starting dienes appears inconsequential, which removes the need to prepare the substrates in high stereoisomeric purity. For example, the reaction of diene $(3 E, 5 Z)-13 a$ with benzaldehyde gave results that are comparable with its $(E, E)$-counterpart [Eq. (4), compare with Scheme 4]. A mixture of all four possible stereoisomers of $13 \mathbf{a}$ can also be used with similar efficiency [Eq. (5)].
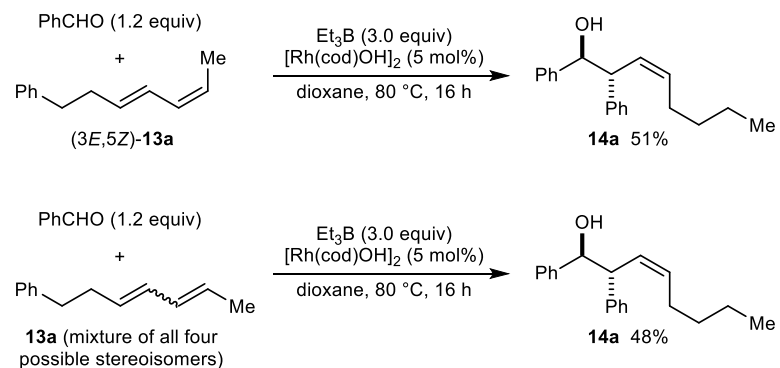


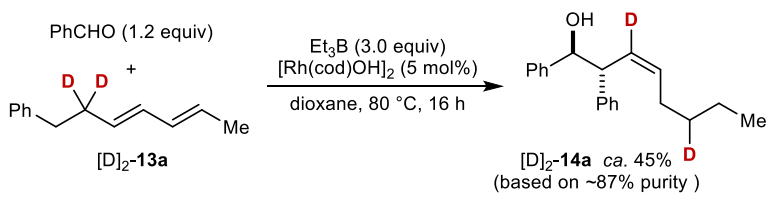

The reaction of benzaldehyde with the doubly deuteriumlabeled diene $[D]_{2}-13 a$ gave homoallylic alcohol $[D]_{2}-14 a$ in $\leq 87 \%$ purity, in which one deuterium atom was transferred to the homoallylic methylene carbon, with no evidence of deuteration at other sites [Eq. (6)]. This overall 1,4-deuterium shift is consistent with the mechanism shown in Scheme 2 (see the Supporting Information for details)

Finally, this process is not limited to aldehyde electrophiles. Although cyclic imines (Scheme 1C) and ketones are not suitable substrates, diene 15 reacted with the formaldimine derived from cracking of 1,3,5-tris(4-methoxyphenyl)-1,3,5triazinane to give homoallylic amine 16 in 52\% yield [Eq. (7)]. The inclusion of $3 \AA$ molecular sieves was beneficial in increasing the yield of this reaction.

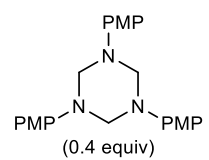<smiles>C=C/C=C/CCc1ccccc1</smiles>
$\mathrm{Et}_{3} \mathrm{~B}(3.0$ equiv)
$\left[\begin{array}{c}\mathrm{Rh}(\mathrm{cod}) \mathrm{OH}]_{2}(5 \mathrm{~mol} \%) \\ \underset{\text { dioxane, } 3 \AA \mathrm{MS}}{80^{\circ} \mathrm{C}, 24 \mathrm{~h}}\end{array}\right.$

15

In conclusion, we have reported the rhodium-catalyzed reductive nucleophilic allylation of aldehydes or an imine with 1,3-dienes, in which carbon-carbon bond formation occurs at a site remote from the initiation site by the overall net migration of allylrhodium species. This study illustrates the potential utility of allylmetal chain walking in remote $\mathrm{C}-\mathrm{H}$ functionalization, which complements much more well-known alkylmetal chain walking processes. Compared with our previous work (Scheme 1C), ${ }^{[4 b]}$ we have shown that chain walking can proceed through greater distances (up to eight methylene units). Furthermore, an expanded range of functional groups was shown to promote chain walking, which includes esters, amides, and (hetero)arenes. Our future work will include the development of enantioselective variants of this process. ${ }^{[11]}$

Received: ((will be filled in by the editorial staff)) Published online on ((will be filled in by the editorial staff))

\section{Acknowledgements}

This work was supported by the Engineering and Physical Sciences Research Council [grant numbers EP/M50810X/1 and $\mathrm{EP} / \mathrm{K} 504348 / 1]$; the Basque Country government; the Leverhulme Trust [grant number RPG-2016-341]; and GlaxoSmithKline.

Keywords: allylation $\cdot$ chain walking $\cdot$ homogeneous catalysis $•$ isomerization • rhodium

[1] For selected reviews: a) R. Breslow, Acc. Chem. Res. 1980, 13, 170 177. b) H. Schwarz, Acc. Chem. Res. 1989, 22, 282-287. c) H. Jiang, L. Albrecht, K. A. Jorgensen, Chem. Sci. 2013, 4, 2287-2300. d) I.
Franzoni, C. Mazet, Org. Biomol. Chem. 2014, 12, 233-241. e) M Vilches-Herrera, L. Domke, A. Börner, ACS Catal. 2014, 4, 1706-1724. f) G. Qiu, J. Wu, Org. Chem. Front. 2015, 2, 169-178. g) A. Vasseur, J. Bruffaerts, I. Marek, Nature Chem. 2016, 8, 209-219. h) J. Bruffaerts, D. Pierrot, I. Marek, Org. Biomol. Chem. 2016, 14, 10325-10330. i) H. Sommer, F. Juliá-Hernández, R. Martin, I. Marek, ACS Cent. Sci. 2018 4, 153-165.

[2] For selected, recent examples of chain walking of alkylmetal species, see: a) G. C. Tsui, M. Lautens, Angew. Chem., Int. Ed. 2010, 49, 8938 8941. b) A. Renaudat, L. Jean-Gérard, R. Jazzar, C. E. Kefalidis, E. Clot, O. Baudoin, Angew. Chem., Int. Ed. 2010, 49, 7261-7265. c) E. W. Werner, T.-S. Mei, A. J. Burckle, M. S. Sigman, Science 2012, 338, 1455-1458. d) W.-C. Lee, C.-H. Wang, Y.-H. Lin, W.-C. Shih, T.-G. Ong, Org. Lett. 2013, 15, 5358-5361. e) A. Millet, P. Larini, E. Clot, O. Baudoin, Chem. Sci. 2013, 4, 2241-2247. f) T.-S. Mei, H. H. Patel, M. S. Sigman, Nature 2014, 508, 340-344. g) T. Yamakawa, N. Yoshikai, Chem. Asian. J. 2014, 9, 1242-1246. h) J. S. Bair, Y. Schramm, A. G Sergeev, E. Clot, O. Eisenstein, J. F. Hartwig, J. Am. Chem. Soc. 2014, 136, 13098-13101. i) E. Larionov, L. Lin, L. Guénée, C. Mazet, J. Am. Chem. Soc. 2014, 136, 16882-16894. j) C. M. Filloux, T. Rovis, J. Am. Chem. Soc. 2015, 137, 508-517. k) L. Lin, C. Romano, C. Mazet, J. Am. Chem. Soc. 2016, 138, 10344-10350. I) H. H. Patel, M. S. Sigman, J. Am. Chem. Soc. 2016, 138, 14226-14229. m) S. Dupuy, K.-F. Zhang, A.-S. Goutierre, O. Baudoin, Angew. Chem., Int. Ed. 2016, 55, 1479314797. n) Y. He, Y. Cai, S. Zhu, J. Am. Chem. Soc. 2017, 139, 10611064. o) F. Juliá-Hernández, T. Moragas, J. Cornella, R. Martin, Nature 2017, 545, 84-88. p) Y. Ebe, M. Onoda, T. Nishimura, H. Yorimitsu, Angew. Chem., Int. Ed. 2017, 56, 5607-5611. q) M. Gaydou, T. Moragas, F. Juliá-Hernández, R. Martin, J. Am. Chem. Soc. 2017, 139, 12161-12164. r) F. Zhou, J. Zhu, Y. Zhang, S. Zhu, Angew. Chem., Int. Ed. 2018, 57, 4058-4062. s) C. Romano, C. Mazet, J. Am. Chem. Soc. 2018, 140, 4743-4750.

[3] For metal migrations by iterative allylic $\mathrm{C}-\mathrm{H}$ activations/hydride reinsertions of zirconacyclopropanes, see: a) N. Chinkov, S. Majumdar I. Marek, J. Am. Chem. Soc. 2002, 124, 10282-10283. b) N. Chinkov, S Majumdar, I. Marek, J. Am. Chem. Soc. 2003, 125, 13258-13264. c) N Chinkov, A. Levin, I. Marek, Angew. Chem., Int. Ed. 2006, 45, 465-468. d) A. Masarwa, D. Didier, T. Zabrodski, M. Schinkel, L. Ackermann, I. Marek, Nature 2014, 505, 199-203. e) A. Vasseur, L. Perrin, O. Eisenstein, I. Marek, Chem. Sci. 2015, 6, 2770-2776.

[4] a) T. Smejkal, H. Han, B. Breit, M. J. Krische, J. Am. Chem. Soc. 2009 131, 10366-10367. b) J. I. Martínez, J. J. Smith, H. B. Hepburn, H. W. Lam, Angew. Chem., Int. Ed. 2016, 55, 1108-1112.

[5] a) Y. Luo, H. B. Hepburn, N. Chotsaeng, H. W. Lam, Angew. Chem., Int. Ed. 2012, 51, 8309-8313. b) H. B. Hepburn, N. Chotsaeng, Y. Luo, H. W. Lam, Synthesis 2013, 45, 2649-2661. c) H. B. Hepburn, H. W. Lam, Angew. Chem., Int. Ed. 2014, 53, 11605-11610. d) M. Callingham, B. M. Partridge, W. Lewis, H. W. Lam, Angew. Chem., Int. Ed. 2017, 56, $16352-16356$

[6] M. Kimura, D. Nojiri, M. Fukushima, S. Oi, Y. Sonoda, Y. Inoue, Org. Lett. 2009, 11, 3794-3797.

[7] The relative configurations of products $2 \mathrm{f}$ and $14 \mathrm{a}$ were determined by converting them into cyclic derivatives, followed by ${ }^{1} \mathrm{H}$ NMR analysis of vicinal coupling constants. See the Supporting Information for details. The relative configurations of the remaining products were assigned by analogy.

[8] Under different reaction conditions, the reaction of rhodium hydrides with activated 1,3-dienes has been proposed to occur via 1,4 hydrorhodation. See: R. Dada, Z. Wei, R. Gui, R. J. Lundgren, Angew. Chem., Int. Ed. 2018, 57, 3981-3984.

[9] These other products were generally not isolated, except in the case of the reaction producing $\mathbf{1 4 a}$ (see Scheme 4). See the Supporting Information for details.

[10] The reasons for halogen-containing substrates being ineffective are not currently known, but one possibility is undesired oxidative addition of $\mathrm{Rh}(\mathrm{I})$ with the carbon-halogen bond. For selected examples of oxidation addition of Rh(I) with alkyl or aryl halides, see: a) S. Gatard, R. Çelenligil-Çetin, C. Guo, B. M. Foxman, O. V. Ozerov, J. Am. Chem. Soc. 2006, 128, 2808-2809. b) C. Tejel, M. A. Ciriano, J. A. López, S. 
Jiménez, M. Bordonaba, L. A. Oro, Chem. Eur. J. 2007, 13, 2044-2053. c) T. M. Douglas, A. B. Chaplin, A. S. Weller, Organometallics 2008, 27, 2918-2921. d) J. Wang, X. Tong, X. Xie, Z. Zhang, Org. Lett. 2010, 12 5370-5373. e) Y. Jiao, W. W. Brennessel, W. D. Jones, Organometallics 2015, 34, 1552-1566. f) A. König, C. Fischer, E.
Alberico, C. Selle, H.-J. Drexler, W. Baumann, D. Heller, Eur. J. Inorg Chem. 2017, 2040-2047.

[11] Using various chiral diene-rhodium complexes in these reactions led to low conversions and enantioselectivities. 


\section{COMMUNICATION}

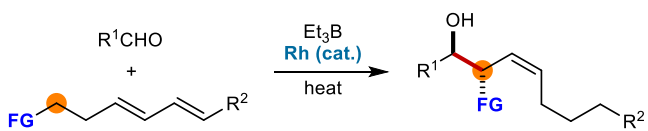

FG = ester, amide, arene, heteroarene

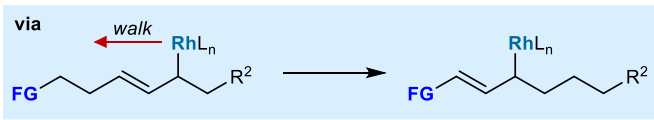

A. Groves, J. I. Martínez, J. J. Smith, H. W. Lam*

\section{Page No. - Page No.}

Remote Nucleophilic Allylation by Allylrhodium Chain Walking

Allylrhodium species obtained from hydrorhodation of 1,3-dienes undergo chain walking toward esters, amides, or (hetero)arenes over distances of up to eight methylene units. The final, more highly conjugated allylrhodium species undergo nucleophilic allylation with aldehydes and an imine to give Z-homoallylic alcohols and amines, respectively. 